\title{
Educação em tempos de pandemia: desafios e possibilidades
}

\author{
Education in times of pandemic: challenges and possibilities
}

Elmara Pereira de Soura ${ }^{1}$

\begin{abstract}
Resumo: A pandemia de COVID-19 impôs uma nova ordem, um outro ritmo para a humanidade. O nosso cotidiano mudou e a escola tem tentado se ressignificar. A proposta deste artigo é apresentar alguns desafios e possibilidades da educação em tempos de pandemia e suscitar diálogos e reflexões sobre ensino remoto, educação a distância, educação online e sobre as potencialidades do uso das tecnologias digitais em rede para a formação de pessoas críticas, criativas, autônomas, autoras, em um tempo que o exercício da cidadania se impõe. Consideramos que as tecnologias da informação e comunicação, as plataformas virtuais de aprendizagem, as redes sociais devem ser vistos como propulsores da criação de novas relações com a informação, com o tempo, com o espaço, consigo mesmo e com os outros. Em tempos de pandemia, mais do que nunca, a educação é convocada a se singularizar, a se reinventar buscando outras possibilidades pelo uso das tecnologias digitais e pela habitação nos ambientes virtuais de aprendizagem. O artigo apresenta, também, a experiência dos cursos online do Centro Juvenil de Ciência e Cultura de Vitória da Conquista-Bahia, escola pública de educação complementar vinculada à Secretaria de Educação do Estado Bahia.
\end{abstract}

Palavras-chave: Tecnologias digitais. Educação online. Pandemia.

\begin{abstract}
The COVID-19 pandemic has imposed a new order, another rhythm for humanity. Our daily life has changed and the school has tried to resign itself. The goal of this paper is to present some challenges and possibilities of education in times of pandemic and to raise dialogues and reflections on remote education, distance education, online education and on the potentialities of the use of networked digital technologies for the formation of critical, creative, autonomous, authoring people, in a time when the exercise of citizenship is imposed. We consider that information and communication technologies, virtual learning platforms, social networks should be seen as propelling the creation of new relationships with information, with time, with space, with oneself and with others. More than ever, education is called to singularize itself, to reinvent itself seeking other possibilities through the use of digital technologies and housing in virtual learning environments. The paper also presents the experience of online courses of Youth Center for Science and Culture of Vitória da Conquista-Bahia, a public school of complementary education linked to Bahia Department of Education.
\end{abstract}

Keywords: Digital Technologies. Online education. Pandemic.

\footnotetext{
1 Secretaria de Educação do Estado da Bahia. Doutora em Difusão do Conhecimento (UFBA), com estágio na Universidad Nacional de Educación a Distancia - Espanha, Mestre em Educação (UFRGS), com ênfase em tecnologias na educação, vice-diretora do Centro Juvenil de Ciência e Cultura de Vitória da Conquista - BA. E-mail: elmarasouza@gmail.com.
} 


\section{Introdução}

O sonho do Raul, o maluco beleza, parece ter se tornado realidade. Mas, não foi apenas "um dia em que a Terra parou, um dia em que todas as pessoas do planeta inteiro resolveram que ninguém ia sair de casa" (SEIXAS, 1977). Milhões e milhões de pessoas passaram meses em isolamento social. Em 11 de março de 2020, a Organização Mundial da Saúde (OMS) declarou que o mundo passava por uma pandemia. Três meses e meio após este anúncio já havia 9.454.051 de casos confirmados de COVID-19 e quase meio milhão de mortes em todo o mundo (WHO, 2020).

Vivemos uma crise sem precedentes. A pandemia do coronavírus chegou nos impondo uma nova ordem, um outro ritmo para a humanidade. O caos se instalou. No Brasil, além da grave crise sanitária, ainda passamos por profundas crises econômica e política. Para tentar entender este momento, precisamos dialogar com um turbilhão de sentimentos, assim como, com teorias e práticas que possam nos ajudar a encontrar um pouco de ordem no caos. Neste caso, as teorias e práticas não nos auxiliam apenas a refletir sobre o momento da pandemia, e, em especial, sobre a educação em tempos de COVID-19, mas a produzir, no contexto da educação, outras possibilidades, outros acontecimentos, outros devires ${ }^{2}$. O que importa agora, não é "nem vencer o caos nem fugir dele, mas conviver com ele e dele tirar possibilidades criativas" (GALLO, 2008, p. 49).

No período da pandemia, novas relações afetivas e profissionais foram criadas e ressignificadas, muitas pessoas passaram a trabalhar remotamente; famílias passaram a conviver cotidianamente com vários conflitos; pessoas ficaram afastadas de entes queridos para se proteger e proteger o outro; muitos continuaram nas suas atividades por serem essenciais, por não terem outra opção para se manter ou mesmo por não acreditarem que o vírus é real. Enfim, é uma nova realidade que se apresenta. Mas, e a escola? Quais os impactos da pandemia na educação? E os professores e professoras, que, como quaisquer outros cidadãos, passam por todas estas dificuldades, como estão vivenciando esta nova realidade? Quais os impactos e desafios da quarentena para escolas, estudantes e professores? Estas questões nos instigam a continuar pesquisando e vivenciando a educação em tempos de pandemia.

Segundo dados da PNAD (IBGE, 2018), 20,9\% dos domićlíos brasileiros não têm acesso à internet, isso significa cerca de 15 milhões de lares. Em 79,1\% das residências que têm acesso à rede, o celular é o equipamento mais utilizado e encontrado em 99,2\% dos domicílios, mas muitas famílias compartilham um único equipamento. Outra realidade que não podemos desconsiderar é que as casas das classes médias e alta têm uma estrutura privilegiada para o desenvolvimento de atividades escolares. Porém, as residências das classes populares se configuram, em geral, com poucos cômodos onde convivem várias pessoas, tornando-se difícil a dedicação dos alunos às atividades escolares. A pesquisa TIC Kids Online Brasil (CETIC, 2019) mostra que 11\% das crianças e adolescentes de 9 a 17 anos não têm

2 O devir é o processo do desejo e se afirma na invenção. "Devir é jamais imitar, nem fazer como, nem ajustar-se a um modelo, seja ele de justiça ou de verdade". (DELEUZE,1998, p. 10). 
acesso a internet, correspondendo a 3 milhões de pessoas, sendo que 1,4 milhão nunca acessou a rede. Estes dados enfatizam um dos desafios da educação no período da pandemia, que é o acesso das pessoas à rede internet banda larga para continuarem aprendendo e ensinando.

Com base nesta realidade, este artigo, escrito no calor da pandemia, tem o objetivo de suscitar algumas reflexões sobre educação remota, educação a distância, educação online e sobre as possibilidades e os desafios do uso das tecnologias digitais na educação para a formação de pessoas críticas, criativas, autônomas, autoras, em um tempo em que o exercício da cidadania se impõe.

\section{Alguns desafios}

Durante a quarentena imposta pela COVID-19, como professora-pesquisadora, tenho vivenciado dois movimentos distintos, mas experienciados ao mesmo tempo: o de implicação e o de explicação. $O$ primeiro, dobrando-me para dentro do problema, implicando-me no contexto da educação em tempos de pandemia, solidarizando-me com as famílias das vítimas e experimentando sentimentos de angústia, de medo, de tensão, de cobranças (do outro e nossas) para sermos produtivos e vivenciando as tensões próprias desta realidade. O segundo movimento é o de dobrar-me para fora, fazer o exercício exotópico (BAKHTIN, 2000), ou seja, tentar fazer um exercício de estranhamento, de distância do problema para poder explicar os acontecimentos, o que foi e está sendo vivenciado por professores, no fazer docente, e por estudantes fora do espaço físico da escola. Neste movimento de implicação e explicação, vamos refletindo sobre a educação neste tempo e compartilhando com o outro as nossas reflexões.

A pandemia impôs grandes desafios para professores e estudantes, em especial, na educação básica. Como manter os vínculos com os alunos sem estar no mesmo espaço físico? Como utilizar as tecnologias da informação e comunicação (TIC) para aprender e ensinar? Como utilizar estas tecnologias digitais em rede na educação em um país tão desigual quando o assunto é acesso à internet e conexão de qualidade? Estas são perguntas que nos inquietam e nos fazem pensar sobre novas educações (PRETTO, 2005), ou seja, outras possibilidades que possam superar o modelo tradicional, bancário (FREIRE, 2011) de educação.

Apesar das TIC já fazerem parte, direta ou indiretamente, da rotina das escolas e da realidade de muitos professores e estudantes, a utilização delas no período de pandemia, para substituir os encontros presenciais, tem encontrado vários desafios, entre eles: a infraestrutura das casas de professores e estudantes; as tecnologias utilizadas; o acesso (ou a falta dele) dos estudantes à internet; a formação dos professores para planejar e executar atividades online.

Consideramos que as TIC, os ambientes virtuais de aprendizagem (AVA), as redes sociais, que atualmente fazem parte do domínio cognitivo de muitos de nós, não devem ser considerados como simples objetos, tampouco como soluções para antigos problemas. Acima de tudo, devem ser vistos como propulsores da criação de novas relações com a informação, com o tempo, com o espaço, consigo mesmo e com os outros. Portanto, mais do que nunca, a educação é convocada a se singularizar, a se reinventar buscando outras possibilidades pelo uso das TIC e pela habitação nos AVA. 
Sabemos que mudanças não são simples, em especial, na escola, espaço, por um lado, privilegiado para a inovação e transformação social, mas, por outro lado, com um currículo e metodologias profundamente tradicionais (SANTOS, 2006). Em busca de soluções imediatas para manter as aulas e os vínculos com os estudantes, escolas têm utilizado o que está sendo chamado de "ensino remoto", termo pouco utilizado no Brasil até o início da pandemia. Mas, o que é este ensino remoto? É a mesma educação a distância ou educação online? Passemos, então, a refletir sobre esses conceitos.

\section{Ensino remoto}

Com a emergência da pandemia, escolas precisaram se organizar para migrar para o ensino com o uso das tecnologias digitais. Esta migração gerou uma transposição de práticas e metodologias do ensino presencial para as plataformas virtuais de aprendizagem, o chamado ensino remoto. Segundo Moreira e Schlemmer (2020, p. 9), no ensino remoto

[...] o ensino presencial físico (mesmos cursos, currículo, metodologias e práticas pedagógicas) é transposto para os meios digitais, em rede. O processo é centrado no conteúdo, que é ministrado pelo mesmo professor da aula presencial física. Embora haja um distanciamento geográfico, privilegia-se o compartilhamento de um mesmo tempo, ou seja, a aula ocorre num tempo síncrono, seguindo princípios do ensino presencial. A comunicação é predominantemente bidirecional, do tipo um para muitos, no qual o professor protagoniza vídeo-aula ou realiza uma aula expositiva por meio de sistemas de webconferência. Dessa forma, a presença física do professor e do aluno no espaço da sala de aula geográfica são substituídas por uma presença digital numa sala de aula digital. No ensino remoto ou aula remota o foco está nas informações e nas formas de transmissão dessas informações.

Nesse sentido, o ensino remoto transferiu o que já se fazia na sala de aula presencial e, em muitos casos, aflorou uma perspectiva de educação instrucionista, conteudista. Temos acompanhado crianças e adolescentes cansados por ficarem horas diante da tela do computador assistindo aulas e fazendo atividades. Neste tipo de ensino, que é utilizado em tempos de guerra, tragédias naturais ou emergência, o potencial das tecnologias digitais em rede é subutilizada, visto que as TIC, prioritariamente, são utilizadas para transmitir as informações através de aulas expositivas via ferramentas de webconferência ou videoaulas.

Segundo pesquisa do Instituto Península (2020), 88\% dos professores nunca tinham dado aula de forma remota e $83,4 \%$ não se sentem preparados. Observamos que mesmo os professores que já utilizavam as tecnologias digitais como apoio ao ensino presencial encontraram dificuldade para se adaptar ao ensino remoto, visto que muitos não têm infraestrutura adequada em suas casas, tampouco formação específica para atuar na docência online. A utilização das tecnologias digitais em rede na educação evidencia que os ambientes virtuais modificam o domínio sobre o fazer docente praticado na modalidade presencial, pois são outros espaços e tempos pedagógicos que se apresentam.

Apesar disto, não perdemos de vista o primeiro e fundamental princípio de que a formação de professores é antes uma práxis que uma teoria sobre uma prática. O ensino remoto tornou-se um desafio para esses profissionais que precisaram aprender na prática a usar as TIC para desenvolver as suas aulas. O ensino remoto provocou um aumento do nível de ansiedade dos professores, além de sobrecarga de 
trabalho (PENÍNSULA, 2020). Estas consequências demonstram a necessidade do apoio técnico e psicológico aos professores.

Segundo Santos (2020), o ensino remoto tem deixado suas marcas, em alguns casos, permitindo encontros afetuosos e boas dinâmicas curriculares, e, em outros, tem repetido modelos massivos subutilizando os potenciais da cibercultura na educação. Os modelos de educação em massa são característicos da educação a distância $(\mathrm{EaD})$ tradicional, com veremos na próxima seção.

\section{Educação a distância}

Desde a definição da EaD como modalidade de ensino pela Lei de Diretrizes e Bases da Educação Nacional (LDB 9394\96), passando pelas metas do Plano Nacional de Educação, até a criação da Universidade Aberta do Brasil (UAB,) em 2006, são várias as ações normativas de execução que vão incorporando a $\mathrm{EaD}$ ao contexto educacional brasileiro.

A EaD representa uma modalidade de ensino que vem sendo utilizada há muito tempo. Inicialmente, utilizava-se a correspondência como tecnologia mediadora entre aluno e professor. Depois chegaram o rádio e as TVs Educativas, que foram importantes para a educação brasileira nas décadas de 1960 a 1990, pois auxiliavam na qualificação de muitos trabalhadores. Esse tipo de educação a distância de massa ainda tem reflexos atualmente nos cursos que utilizam tecnologias digitais.

Com os ambientes online, muitos programas de EaD migraram seus desenhos para as tecnologias digitais da informação e comunicação (TDIC), mantendo a mesma lógica comunicacional das mídias de massa que separa os sujeitos dos processos de criação dos conteúdos e do próprio desenho didático (SANTOS, 2009). Assim, o paradigma educacional, em muitos cursos EaD, ainda estão centrados na pedagogia da transmissão, na lógica da mídia de massa, na autoaprendizagem e nos modelos de tutoria reativa. Somente a transposição do que já se fazia com o uso das mídias de massa para as tecnologias digitais interativas e em rede não configura mudança no processo educacional.

Cabe, nestas reflexões, no contexto da $\mathrm{EaD}$ e do ensino remoto, um olhar crítico à concepção produtivista de formação, que visa "en(formar)", controlar as pessoas como na era industrial da produção em massa. Porém, não podemos deixar de afirmar que em qualquer espaço social, como o ambiente virtual de aprendizagem, pode haver resistência e surgir brechas, linhas de fuga ${ }^{3}$ ao sistema hegemônico.

Passemos, então, a pensar a educação a partir da invenção de outras metodologias e desenhos que formam e se formam no movimento da práxis da educação online.

\section{Educação online e educação (a distância) desterritorializada}

A educação online é uma abordagem didático-pedagógica (SANTOS, 2009; PIMENTEL, 2020). Segundo Santos (2009), a educação online é um fenômeno da cibercultura e não uma evolução da EaD e traz, em potência, o exercício da autoria, o favorecimento da autonomia, da comunicação colaborativa em rede, da interatividade, do diálogo, conforme princípios que a fundamenta (Figura 1). Na educação online,

\footnotetext{
${ }^{3}$ Com base na teoria deleuzo-guattariana, a linha de fuga é o que escapa ao domínio do poder, do capital. A linha de fuga tem um caráter criador e podemos considerar como um fenômeno de resistência a todo tipo de poder estabelecido.
} 
os ambientes virtuais de aprendizagem ${ }^{4}$ são lugares de produção do conhecimento, onde encontros síncronos e, especialmente, assíncronos acontecem.

Figura 1 - Princípios da Educação online

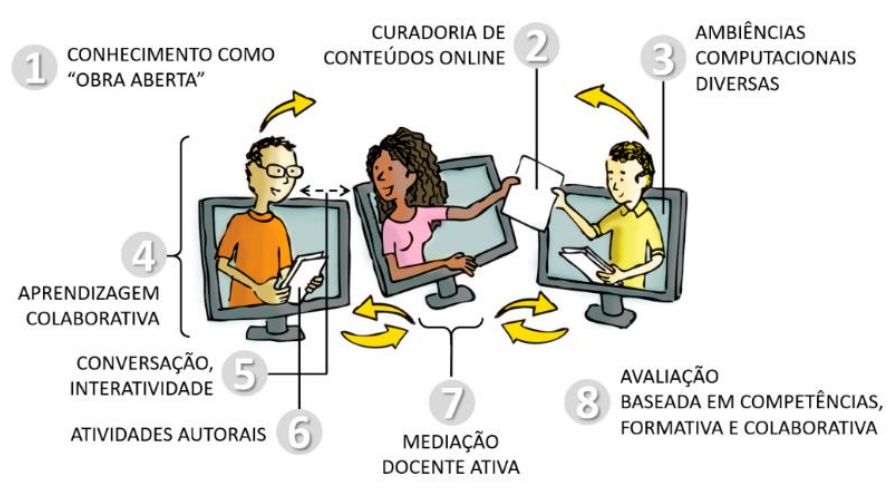

Fonte: Pimentel e Carvalho (2020).

Na educação online, o AVA é um espaço de encontro, espaço de produção de subjetividade. Se não houver diálogo, se não houver espaço para os afetos, o ambiente não passará de uma plataforma. A interatividade, os movimentos, as relações no AVA e para além dele é que produzem o ambiente.

A prática da educação online e da educação (a distância) desterritorializada ${ }^{5}$ (SOUZA, 2013, 2018) pode favorecer a implantação de espaços de aprendizagem coletiva e colaborativa, desvinculando-se da perspectiva homogeneizadora e oportunizando aos professores e estudantes o acesso à (in)formação, à autoria e à produção de conhecimentos.

Com base nos princípios da educação online e da educação (a distância) desterritorializada, a equipe o Centro Juvenil de Ciência e Cultura (CJCC) de Vitória da Conquista foi desafiada a desenvolver os seus cursos online no período da pandemia.

\section{Experiência dos cursos online do CJCC de Vitória da Conquista}

Os CJCC são escolas vinculadas à Secretaria de Educação do Estado da Bahia que atuam como laboratórios pedagógicos dedicados à educação complementar, com o objetivo de "promover o acesso dos estudantes às temáticas contemporâneas" (BAHIA, 2011). Os Centros têm natureza interescolar, ou seja, recebem estudantes das escolas regulares em contraturno e oferecem uma variedade de atividades e cursos interdisciplinares para livre escolha de alunos do ensino médio. Estes cursos são oferecidos em três ciclos durante o ano, com duração de, aproximadamente, três meses cada ciclo.

\footnotetext{
${ }^{4}$ Nos nossos estudos e práticas, diferenciamos AVA de plataforma de aprendizagem. AVA é um dispositivo de produção de subjetividade, que é a combinação do visível, invisível, dizível, do silêncio, das forças, atitudes, relações e linhas, que conectam as pessoas que o habitam e que pode proporcionar afetos alegres e tristes, aumentando ou diminuindo a potência de agir de cada pessoa (SOUZA, 2013, p. 45). Plataforma de aprendizagem é o espaço virtual estático, onde não há pessoas interagindo, construindo conhecimentos coletivamente.

5 A educação (a distância) desterritorializada (SOUZA, 2013) é aquela que resiste aos fluxos instituídos da EaD tradicional, pois é rizomática e não está preocupada com a instauração de nenhuma falsa totalidade. Não interessa à essa educação criar modelos, propor caminhos, impor soluções; o que importa é criar conexões, redes, "rizomatizar", singularizar.
} 
Em março de 2020, iniciamos o primeiro ciclo oferecendo dez cursos interdisciplinares: Animese, Aventuras em Série, F5, No mundo da lua, Mutantes, Studio Plantas, Empreendendo, Fotoclick, Robótica, Loucos por ciência ${ }^{6}$. Após duas semanas de encontros presenciais veio a pandemia e a necessidade de isolamento social. E agora, o que fazer? Após muitas discussões, a equipe decidiu continuar os cursos utilizando o ambiente virtual de aprendizagem e as redes sociais. Já utilizávamos a plataforma Moodle como apoio aos cursos presencial, mas esta foi a primeira experiência com cursos totalmente online.

Foram vários os desafios neste percurso. O primeiro foi desenvolver, em pouco tempo, os cursos para o AVA utilizando o potencial das tecnologias digitais, das redes sociais e dos aplicativos para dispositivos móveis. Os cursos foram, originalmente, concebidos para a educação presencial, por isso, eles tiveram que ser ressignificados, não havendo apenas uma simples transposição do presencial para o AVA. As atividades foram criadas para que os estudantes pudessem interagir, dialogar, produzir conhecimentos coletiva e colaborativamente em/na rede. Não foi uma tarefa fácil. Mas, como o CJCC já faz uma educação diferente com base nos princípios do construcionismo e da aprendizagem criativa (SOUZA; MOURA, 2018), os professores estão abertos a experimentar caminhos inovadores e aprender com o outro.

Nesta perspectiva, desenvolvemos um desenho didático no AVA com atividades assíncronas, interativas e colaborativas, assim como, atividades com o uso de aplicativos e redes sociais favorecendo a autoria, o diálogo, o movimento dos estudantes por diversos espaços virtuais e contemplando os pilares que fundamentam o CJCC: o estudante é autor de sua jornada; a escola é conexão; o conhecimento é transmídia; aprender é divertido (BAHIA, 2011).

O desafio mais complexo neste percurso, na nossa visão, é a conectividade. O período da pandemia escancarou as grandes desigualdades existentes no Brasil. Alunos das escolas públicas têm muito mais dificuldade de acesso à internet do que os das escolas particulares. Fizemos uma pesquisa e identificamos que 69,1\% dos estudantes matriculados no CJCC têm acesso à internet em casa. Porém, $60 \%$ acessam apenas pelo celular e com uma conexão de baixa qualidade, dificultando a participação nos cursos. Dos cerca de 250 estudantes matriculados nos cursos presenciais do primeiro ciclo, 122 (48,8\%) conseguiram acessar o AVA e participar das atividades online. Apesar de trabalharmos na perspectiva da inclusão e, nestes cursos, mais da metade dos estudantes não terem conseguido participar, consideramos que a experiência foi importante, tanto para os professores quanto para os jovens, pois, apresentou outros caminhos de atuação, conforme nos apresenta os enunciados a seguir:

O curso online foi um divisor de águas. Sou muito grata à equipe de professores do CJCC por nos apresentar caminhos. Agora que vejo, um ciclo se fecha, como uma mandala. Nós aprendemos durante essas dez semanas, a professora Karine nos ensinou, os momentos de caminhar, de correr, parar e voar. (Estudante 1)

Nosso curso foi ótimo. Adorei, essa foi a primeira vez que eu fiz um curso no CJCC e foi uma experiencia inovadora. [...] com essa quarentena eu consegui um refúgio pra me ocupar. (Estudante 2)

\footnotetext{
${ }^{6}$ Estes cursos foram elaborados pelos professores Adriana Sousa, Karla Dias, Karine Brandão, Roberto Andrade e Nicéia Melo. Estão disponíveis em cjccvc.org.
} 
Foram muitas atividades que amei fazer no curso, inclusive a fotografia pelo Google Maps e ter descoberto o envelope, onde trocamos cartas com outras pessoas. A ideia do cartão postal que temos da nossa casa, principalmente com a nossa situação atual. Fotografia é momento e vida. Agradeço à oportunidade ao CJCC, principalmente à professora Adriana. (Estudante 3)

O que eu mais gostei do curso foi o entrosamento da turma, o poder de compartilhar opiniões, pensamentos e todos ouvindo sem julgar. Eu me senti a vontade desde a primeira aula e foi super divertido. Todos os alunos se respeitam. Recomendo muito o curso F5, e Karla é uma professora sensacional. (Estudante 4)

Para encerrar o ciclo e comemorar o São João virtual, foi feito um encontro síncrono, com professores e estudantes, utilizando a ferramenta de webconferência Google Meet. Neste encontro, regado por muito forró, foram desenvolvidas atividades de origami, construção de fogueira de led, apresentação de livro e fotografias produzidos pelos estudantes nos cursos.

O CJCC é uma escola que está, potencialmente, aberta para experimentar outras metodologias que produzam uma realidade diferente das práticas hegemônicas, inventando novos modos de aprender e de ensinar, inclusive em AVA. Invenção, neste contexto, não implica uma iluminação súbita, exige uma prática de experimentação e de problematização das ações. O conhecimento, nesse sentido, não se situa na lógica da transmissão e acumulação de informações, mas na produção de outra realidade. Portanto, no período da pandemia, a experiência dos cursos online do CJCC pode engendrar novos espaços-tempo da educação na perspectiva da educação online, da educação (a distância) desterritorializada e criar possibilidades para o período pós-pandemia, incluindo a educação híbrida.

\section{Conclusão}

A emergência do coronavírus provocou várias mudanças nas nossas vidas e, em relação à educação, mostrou o que já estamos discutindo e estudando há muito tempo: a educação precisa se reinventar. $\mathrm{O}$ ensino conteudista, instrucionista não tem mais espaço na sociedade em que vivemos. Na fase pós-pandemia, é fundamental unir esforços para ultrapassar o ensino baseado na transmissão, no falar-ditar do mestre (SILVA, 2002) e experimentar outras metodologias e práticas que levem em conta o potencial das tecnologias digitais em rede e favoreçam a colaboração, a autonomia, a criatividade e a autoria de professores e estudantes.

No período da pandemia, o mergulho no caos fez parte do nosso cotidiano. Mas, o caos tem potencial para tornar a criação possível. Pensar é vivenciar o caos e criar zonas de possibilidades e potencialidades. Portanto, as reflexões e a experimentação da educação em tempos de Covid 19, como caos, desdobraram-se neste artigo esperando encontrar ressonâncias no leitor para podremos, juntos, lutar por políticas públicas de acesso à internet para todos e por outras educações. 


\section{Referências}

BAHIA. Decreto n ${ }^{\circ}$ 12.829, de 04 de maio de 2011. Centros Juvenis de Ciência e Cultura - CJCC. Salvador, BA.

BAKHTIN, M. Estética da Criação Verbal. 4. ed. São Paulo: Martins Fontes, 2000.

CETIC. TIC Kids Online Brasil. Disponível em: <https://cetic.br/pesquisa/kids-online/> Acesso em jun. 2020.

DELEUZE G.; PARNET, C. Diálogos. São Paulo: Escuta, 1998.

DELEUZE, G.; GUATTARI, F. O que é filosofia?. Rio de Janeiro. Editora 34. 2009.

FREIRE, P. Pedagogia do oprimido. 50. ed. São Paulo: Paz e Terra, 2011.

GALLO, S. Deleuze e a educação. Belo Horizonte: Autêntica, 2008.

IBGE. Pesquisa Nacional por Amostra de Domicílios Contínua - PNAD Contínua 2018. Disponível em: <https://biblioteca.ibge.gov.br/visualizacao/livros/liv101705_informativo.pdf>

MOREIRA, J. A.; SCHLEMMER, E. Por um novo conceito e paradigma de educação digital onlife. Revista UFG, 2020, v.20.

PENÍNSULA, I. Sentimento e percepção dos professores brasileiros nos diferentes estágios do Coronavírus no Brasil. 2020. Disponível em: <https://www.institutopeninsula.org.br/> Acesso em: jun. 2020

PIMENTEL, M.; CARVALHO, F. da S. P. Princípios da Educação Online: para sua aula não ficar massiva nem maçante! SBC Horizontes, maio 2020. Disponível em:

<http://horizontes.sbc.org.br/index.php/2020/05/23/principios-educacao-online/>Acesso em: mai.2020.

PRETTO, N. de L. (Org.). Tecnologia e novas Educações. Salvador/Bahia: Edufba, 2005. v. 1, 230 p.

SANTOS, B. de S. A Gramática do Tempo: para uma nova cultura política. São Paulo: Editora Cortez, 2006.

SANTOS, E. Educação online para além da EAD: um fenômeno da cibercultura. Anais do Congresso Internacional Galego-Português de Psicopedagogia. Universidade do Minho, Braga, Portugal, 2009, p. 5658-5671.

SANTOS, E. EAD, palavra proibida. Educação online, pouca gente sabe o que é. Ensino remoto, o que temos para hoje. Mas qual é mesmo a diferença? Revista Docência e Cibercultura, 2020. Disponível em: <https://www.epublicacoes.uerj.br/index.php/re-doc/announcement/view/1119> Acesso: jun. 2020.

SEIXAS, R. O dia em que a terra parou. 1977. Disponível em: $<$ https://www.letras.mus.br/raulseixas/discografia/o-dia-em-que-a-terra-parou-1977/>. Acesso em jun. 2020.

SOUZA, E. P de. Cartografia da produção de subjetividade em ambiente virtual de aprendizagem para a formação de docentes online. Tese de doutorado. Faculdade de Educação. Universidade Federal da Bahia, 2013.

SOUZA, E. P de. Educação (a distância) desterritorializada e a formação de docentes on-line. In: SALES, M. V. S. Tecnologias e educação a distância: os desafios para a formação. Salvador: Eduneb, 2018.

SOUZA, E. P de; MOURA, L. S. Constructionism as an Epistemological Option in Courses of Youth Center for Science and Culture - Bahia - Brazil. Constructionism 2018, Vilnius, Lithuania.

SILVA, M. Sala de aula interativa. Rio de Janeiro: Quartet, 2002

WHO. World Health Organization. Disponível em: < https://www.who.int/emergencies/diseases/novelcoronavirus-2019> Acesso em jun. 2020. 